\title{
Investigation of Eichornia Natans, Pistia Stratiotes and Nymphaea Lotus in Relation to Their Calorific Values and Elemental Composition for Efficient Biofuel Utilization
}

\author{
Jimoh Afeez Oyeshola ${ }^{1}$, Ijege King Odigiri ${ }^{2}$, Babagana Muktar ${ }^{2}$, Amusan Victor Oluwasanmi ${ }^{3, *}$ \\ ${ }^{1}$ Department of Chemistry, Nigerian Defence Academy, Kaduna, Nigeria \\ ${ }^{2}$ Department of Applied Sciences, Kaduna Polytechnic, Kaduna, Nigeria \\ ${ }^{3}$ Department of Biological Sciences, Nigerian Defence Academy, Kaduna, Nigeria
}

Email address:

hafeezmemo@gmail.com (J. A. Oyeshola),kingijege@gmail.com (I. K. Odigiri),bgmuktar77@gmail.com (B. Muktar), voaplus@yahoo.com (A. V. Oluwasanmi)

${ }^{*}$ Corresponding author

\section{To cite this article:}

Jimoh Afeez Oyeshola, Ijege King Odigiri, Babagana Muktar, Amusan Victor Oluwasanmi. Investigation of Eichornia Natans, Pistia Stratiotes and Nymphaea Lotus in Relation to Their Calorific Values and Elemental Composition for Efficient Biofuel Utilization. Advances in Bioscience and Bioengineering. Vol. 5, No. 5, 2017, pp. 82-85. doi: 10.11648/j.abb.20170505.12

Received: July 2, 2017; Accepted: July 11, 2017; Published: October 30, 2017

\begin{abstract}
The relationship between the high heating values (HHVs) and the elemental contents of some freshwater biomass were studied. The results obtained from the ultimate analysis show that the HHVs of the freshwater biomass is a function of total carbon and hydrogen contents but, a weak function of oxygen, nitrogen and sulphur. Analyses of the experimental results shows that, the HHVs of the biomass tested are not linearly related to their total hydrogen contents but, directly related to their total Carbon contents. HHV's calculated from theoretical correlations using the elemental contents of $\mathrm{C}, \mathrm{H}, \mathrm{N}, \mathrm{S}$ and $\mathrm{O}$ compared well with that of the American Standard of Testing Materials (ASTM) results and also in good agreement with the widely reported values in the acceptable range of $17-21 \mathrm{MJ} / \mathrm{kg}$.
\end{abstract}

Keywords: High Heating Values, Calorific Values, Freshwater, Biomass, Ultimate Analysis

\section{Introduction}

The gradual diminishing of fossil fuel reserves and long lead times in creation of conventional fuels have increased the fear of energy crisis in the near future. Moreover, increased concern about the environment has led to a debate on the use of alternative fuels based on renewable sources [1]. Environmental and ecological problems are the major issues of concern associated with exploitation of these fuels. Another major challenge with these fuels is their unsustainability and projected depletion over the years. Renewable alternative fuels like biomass, reduce greenhouse gas emissions and particulate matter and promotes energy independence, whereas NOx emissions of biomass are comparable with conventional solid fuels. Biomass fuels are considered to maintain overall $\mathrm{CO}_{2}$ balance in the atmosphere [2].
Application of lignocellulosic biomass such as forest residues, agro-wastes, energy grasses, aquatic (freshwater and marine) plants and algae, etc. for bioenergy production seem promising as they are evenly distributed across the globe and have also eliminated initial public perception of food insecurity associated with first generation biofuels which were produced from food materials. In addition, these materials have low levels of sulfur, nitrogen and ash content which make them relatively environmentally friendly $[1,3]$.

The important properties of biomass includes: heating value or calorific value, proximate analysis and ultimate analysis [4]. The determination of the calorific values and percentage of $\mathrm{C}, \mathrm{H}, \mathrm{N}, \mathrm{S}$ and $\mathrm{O}$ of biofuels are important in considering their suitability as environmentally safe energy sources and their potential to produce a particular bioenergy that can be used for industrial and domestic process heat [5]. Several empirical correlations for determining HHV of solid fuels have been proposed since late 1800 s. Over the past 
decade, with the gaining popularity of renewable fuels, researchers have attempted to find empirical correlations for HHV of biomass fuels [6]. Few of the correlations are used in this study. In the correlations, $\mathrm{C}, \mathrm{H}, \mathrm{O}, \mathrm{N}$ and $\mathrm{S}$ represents the carbon, hydrogen, oxygen, nitrogen and sulphur percentages (by weight in dry biomass) in the biomass respectively.

In order to provide a means of quantification of energy content of biomass, this work investigated the relationship between the high heating values and elemental composition of three freshwater biomasses for efficient biofuel utilization.

\section{Materials and Methods}

\subsection{Sampling}

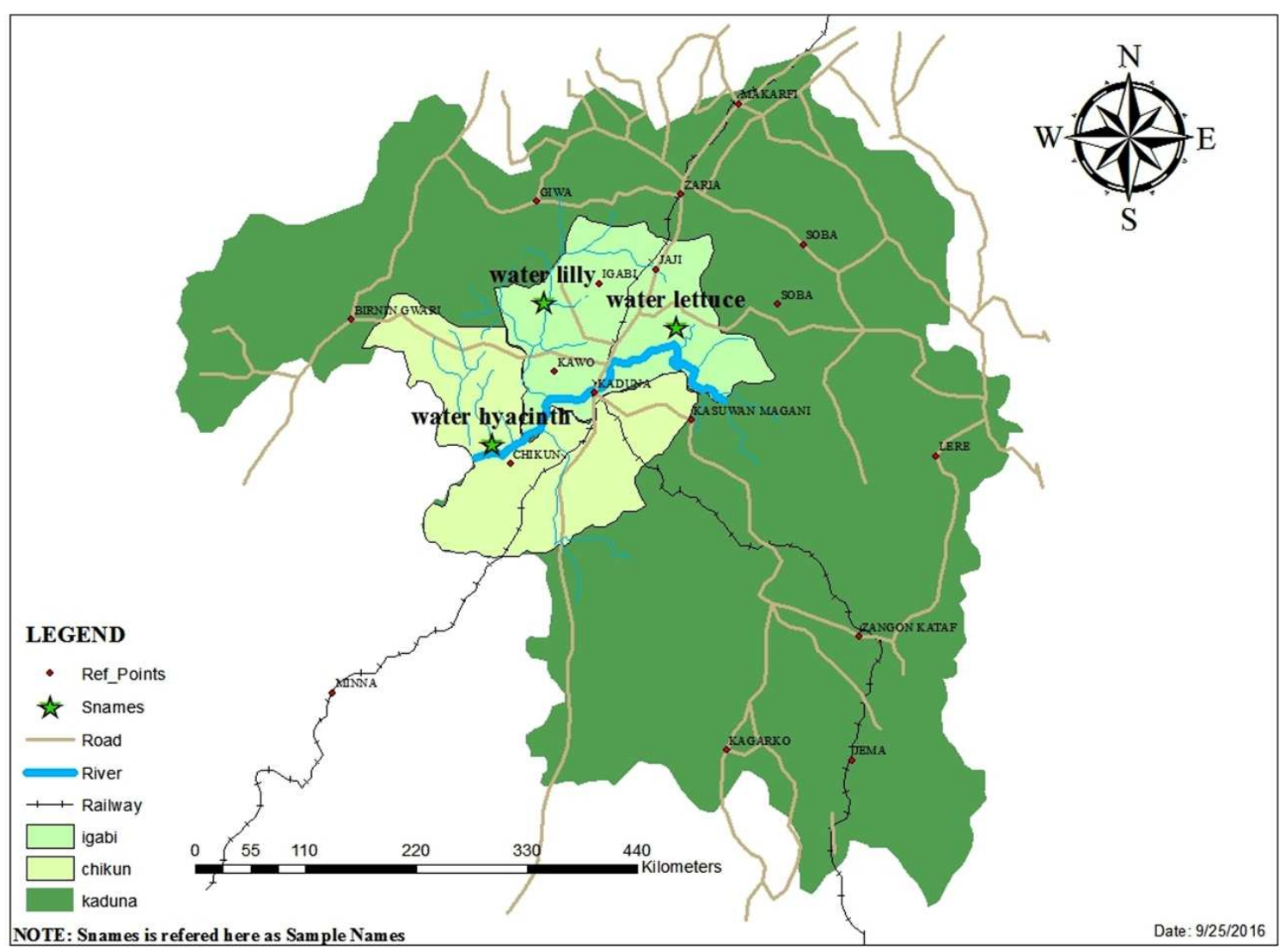

Figure 1. Map of Study Area.

\subsection{Sample Preparation}

The leaves and stems of each plants were cut, separated and washed thoroughly with tap water to remove adhering dirt. The plant was air dried at room temperature, then grinded into powder using a blender and sieved with a $0.4 \mathrm{~mm}$ mesh and kept in a labelled container for further use [7-8].

\subsection{Ultimate Analysis of the Freshwater Biomass}

Estimations of important chemical elements that make up biomass, namely percentage carbon, hydrogen, oxygen, and sulphur, were determined through ultimate analysis. These
The plant samples were obtained within Kaduna metropolis (see Figure 1). They were collected manually using gloved hands and placed in polythene bags, then transported to the laboratory for further preparation. Water Hyacinth was obtained at Ungwan boro in Chikun local government area of Kaduna within longitude $10^{\circ} 30.332^{\prime} \mathrm{N}$ and latitude $007^{\circ} 27.230^{\prime} \mathrm{E}$, Water Lettuce and Water Lilly were obtained at a farmland in Zangon Aya, Igabi Local Government within longitude $10^{\circ} 55.117^{\prime} \mathrm{N}$ and latitude $007^{\circ} 39.733^{\prime} \mathrm{E} ; 10^{\circ} 55.131^{\prime} \mathrm{N}$ and $007^{\circ} 39.577^{\prime} \mathrm{E}$ respectively. The plant samples were authenticated and a voucher number was issued at the herbarium section in the botany department of Ahamdu Bello University, Zaria.
Date: $9 / 25 / 2016$

properties were determined in accordance with ASTM analytical methods as described by Jenkins et al [9]. Nitrogen was determined by the micro-kjeldahl method while ash content of the aquatic biomass was determined using the method described by the Association of Official Analytical Chemists [10].

\subsection{Determination of Calorific Values or High Heating Values (HHVS)}

The determination of calorific values in $\mathrm{MJ} / \mathrm{kg}$ was made using a bomb calorimeter (model 6100 series manufactured by Parr Instrument Company) in the chemical engineering department, Ahmadu Bello University, Zaria. 


\subsection{The Use of Theoretical Equations to Estimate HHVs}

The indirect determination of high heating values (HHVs) of biofuels samples were made from their ultimate analysis results and total ash contents using the equations shown below:

Boie's correlation:

$$
\mathrm{HHV}(\mathrm{MJ} / \mathrm{kg})=0.3517 \mathrm{C}+1.1626 \mathrm{H}+0.1047 \mathrm{O}+0.0628 \mathrm{~N}-
$$

Tillman's correlation:

$$
\mathrm{HHV}(\mathrm{MJ} / \mathrm{kg})=0.4373 \mathrm{C}+1.6701
$$

Channiwala and Parikh's correlation:

$$
\begin{aligned}
\mathrm{HHV}(\mathrm{MJ} / \mathrm{kg})= & 0.3491 \mathrm{C}+1.1783 \mathrm{H}+0.1005 \mathrm{~S}-0.1034 \mathrm{O}- \\
& 0.0151 \mathrm{~N}-0.0211 \text { Ash }
\end{aligned}
$$

Yin's correlation:

$$
\mathrm{HHV}=0.2949 \mathrm{C}+0.8250 \mathrm{H}
$$

\begin{tabular}{|c|c|c|c|c|c|c|c|}
\hline Biomass & $\mathbf{N}(\%)$ & S (\%) & $\mathrm{C}(\%)$ & H (\%) & O (\%) & Ash (\%) & HHV (MJ/kg) \\
\hline E. natans Leaf & $3.89^{\mathrm{bc}}$ & $2.76^{\mathrm{a}}$ & $45.25^{\mathrm{b}}$ & $5.23^{\mathrm{a}}$ & $28.97^{\mathrm{a}}$ & $13.93^{\mathrm{d}}$ & 17.64 \\
\hline E. natans Stem & $2.35^{\mathrm{d}}$ & $0.27^{\mathrm{b}}$ & $52.45^{\mathrm{ab}}$ & $5.64^{\mathrm{a}}$ & $19.53^{\mathrm{ab}}$ & $19.80^{\mathrm{bc}}$ & 20.53 \\
\hline P. stratiotes Leaf & $4.76^{\mathrm{a}}$ & $3.24^{\mathrm{a}}$ & $50.75^{\mathrm{ab}}$ & $5.81^{\mathrm{a}}$ & $12.25^{\mathrm{b}}$ & $23.20^{\mathrm{a}}$ & 18.57 \\
\hline P. stratiotes Stem & $3.33^{\mathrm{c}}$ & $2.29^{\mathrm{a}}$ & $49.56^{\mathrm{ab}}$ & $6.10^{\mathrm{a}}$ & $14.85^{\mathrm{b}}$ & $23.87^{\mathrm{a}}$ & 24.93 \\
\hline$N$. lotus Leaf & $4.13^{\mathrm{ab}}$ & $2.94^{\mathrm{a}}$ & $56.42^{\mathrm{a}}$ & $5.13^{\mathrm{a}}$ & $13.88^{\mathrm{b}}$ & $17.53^{\mathrm{c}}$ & 19.53 \\
\hline N. lotus Stem & $2.24^{\mathrm{d}}$ & $1.71^{\mathrm{ab}}$ & $53.78^{\mathrm{ab}}$ & $4.92^{\mathrm{a}}$ & $15.37^{\mathrm{b}}$ & $22.00^{\mathrm{ab}}$ & 20.98 \\
\hline
\end{tabular}

\section{Results and Discussion}

Table 1 shows the result of ultimate analysis, ash content and the high heating value of the freshwater biomass.

Table 1. Ultimate Analysis of Freshwater Biomass.

*Means that do not share a letter are significantly different $(\mathrm{P}>0.05)$.

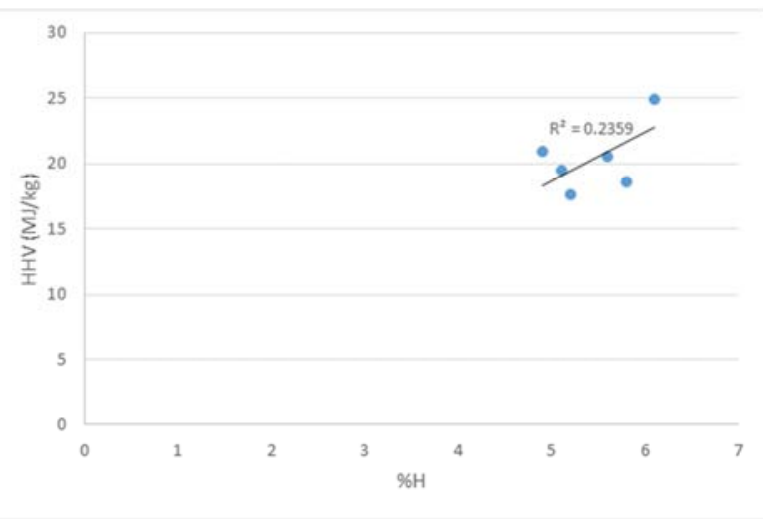

Figure 2. Relationship between HHV and Hydrogen content.

The percentage hydrogen contents, total carbon and high heating values for the biomass is presented in Table 1. A graph of high heating value against total hydrogen and carbon contents is plotted. From the data shown in Table 1 and the trend of data plotted in Figure 2 and 3, it is evident that the higher heating values of the biomass samples is not linearly related to their total hydrogen contents but directly related to their total carbon content, i.e. the higher the carbon content of the biomass, the higher the heat energy to do a useful work. The co-efficient $\mathrm{R}^{2}$, which represent the correlation between HHVs and total hydrogen and carbon contents were calculated as 0.2359 and 0.7385 respectively.
These calculated values show that the relationship between HHVs and total carbon contents is positive/direct while for hydrogen content there is no correlation. These results are in good agreement with the theoretical equations that the high heating value of biomass materials is a very strong function of its fixed carbon content [11-14].

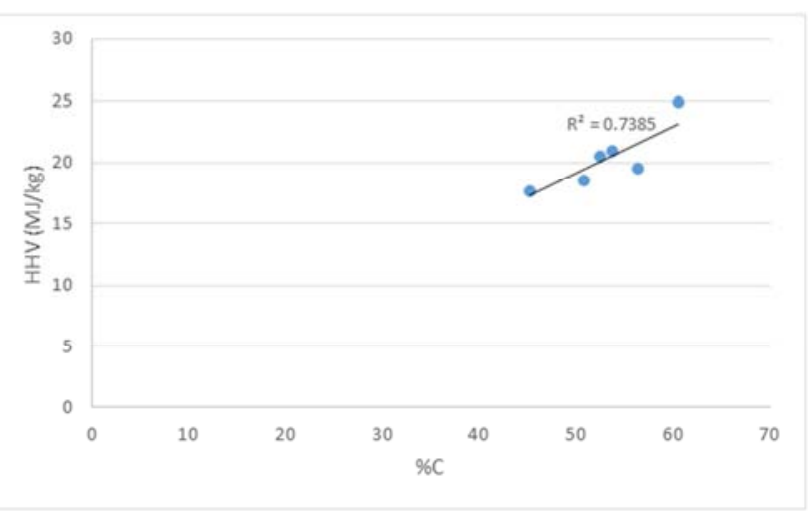

\begin{tabular}{|c|c|c|c|c|c|}
\hline Biomass & HHV (Expt.) & Boie & Channiwala & Tillman & Yin \\
\hline E. natans Leaf & 17.64 & 19.28 & 18.85 & 18.12 & 17.63 \\
\hline E. natans Stem & 20.53 & 22.97 & 22.46 & 21.27 & 20.09 \\
\hline P. stratiotes Leaf & 18.57 & 23.87 & 23.05 & 20.52 & 19.75 \\
\hline P. stratiotes Stem & 24.93 & 23.32 & 22.63 & 20.00 & 19.65 \\
\hline$N$. lotus Leaf & 19.53 & 24.80 & 24.13 & 23.00 & 20.85 \\
\hline N. lotus Stem & 20.98 & 23.22 & 22.63 & 21.85 & 19.90 \\
\hline
\end{tabular}

Figure 3. Relationship between HHV and Carbon content.

Table 2 shows the comparison between experimental high heating values and theoretically calculated high heating values using equation 1-4.

Table 2. Comparison of $H H V$ in $M J / k g$. 
Analysis of the results presented in the table showed that experimental heating values do not excellently agreed with the modeled values as well as the calculated values estimated using theoretical equations [11-14]. The experimental results are considered to be more accurate in this work due to the fact that the results are in good agreement with widely reported HHVs in the range of 17-21 MJ/kg [15]. Theoretical calculated values over predicts HHVs for a number of data points and some few data points matched the computed results.

\section{Conclusion}

The HHVs of the freshwater biomass tested are not a function of their total hydrogen contents but a function of their total carbon contents. The co-efficient $\mathrm{R}^{2}$, which represent the correlation between HHVs and total hydrogen and carbon contents were calculated as 0.2359 and 0.7385 respectively. Yin's correlation gives better results than all other correlations for the freshwater biomass considered in this study. The experimental determined $\mathrm{N}$ and $\mathrm{S}$ contents are comparable to some well-known biomass like corn cobs, rice husk briquettes and other agricultural residues. The total nitrogen measured varies in the range $2.24-4.76(\mathrm{wt} \%)$ and the total sulphur range $0.27-3.24$ (wt\%). It is however recommended that the relationship between the HHVs and total hydrogen/carbon content of some other biomass e.g. marine biomass be investigated so as to confirm if a general statement can be drawn regarding the combustion relationship between biomass HHV and its total carbon or hydrogen content. There is also need to carry out the experiment with the bomb calorimeter for some other biomass in order to verify the major disagreement between the measured and calculated HHVs of biomass.

\section{References}

[1] Nigam PS, Singh A. Production of liquid biofuels from renewable resources. Prog Energy Combust Sci 2011; 37: 5268 .

[2] Srirangan K, Akawi L, Moo-Young M. Towards sustainable production of clean energy carriers from biomass resources. Appl Energy 2012; 100: 172-186.
[3] Zaldivar J, Nielsen J, Olsson L. Fuel ethanol production from lignocellulose: a challenge for metabolic engineering of biocatalysts for fuel ethanol production. Appl Microbiol Biotechnol 2001; (56): 17-34.

[4] Gupta SC, Manhas P. Percentage generation and estimated energy content of municipal solid waste at commercial area of Janipur, Jammu. Environmental Conservation Journal, 2008; 9(1): 27-31.

[5] Kumar J, Pratt BC. Determination of calorific values of some renewable biofuels. Elsevier, Thermochimica Acta 1996; 279: 111-120.

[6] Shashank SN, Czarnowska L, Bogacka M. The influence of compositions of alternative fuels on higher heating values. Archives of Waste Management and Environmental Protection 2015; 17(1): 141-148.

[7] Awasthi M, Kaur J, Rana, S. Bioethanol production through water hyacinth, eichhornia crassipes via optimization of the pretreatment conditions. International Journal of Emerging Technology and Advanced Engineering 2013; 3(3): 42-46.

[8] Galbe M, Zacchi G. Pretreatment of lignocelluloses materials for efficient bioethanol production. Adv. Biochem. Eng. /Biotechnol 2007; 108: 41-65.

[9] Jenkins BM, Baxter LL, Miles TR. Combustion properties of biomass. Fuel Process Technology 1998; 54: 17-46.

[10] AOAC, Official Methods of Analysis of the Association of Official Analytical Chemists, 15th ed.; 1999.

[11] Boie W. Fuel technology calculations. Energie technik 1953; 3: 309-316.

[12] Channiwala SA, Parikh PP. A unified correlation for estimating HHV of solid, liquid and gaseous fuels. Fuel 2002; 81(8): 1051-1063.

[13] Tillman DA. Wood as an energy resources. Fuel 1978; 3(3): 112-123.

[14] Yin CY. Prediction of higher heating values of biomass from proximate and ultimate analyses. Fuel 2011; 90(3): 11281132.

[15] Ismaila A, Zakari IY, Nasiru R, Tijjani BI. Investigation on biomass briquettes as energy source in relation to their calorific values and measurement of their total carbon and elemental contents for efficient biofuel utilization. Advances in Applied Science Research, 2013; 4(4): 303-309. 